\title{
İlkokul Öğretmenlerinin Örgütsel Bağlılık, Örgütsel Sinizm ve Örgütsel Vatandaşlık Davranışları Arasındaki İlişki ${ }^{1}$
}

\author{
Arş. Gör. Alper YORULMAZ* \\ Marmara Üniversitesi, Atatürk Eğitim Fakültesi, Göztepe Kampüsü, \\ Kadıköy / İstanbul / Türkiye
}

\author{
Doç. Dr. Sabri ÇELİK
}

Gazi Üniversitesi, Gazi Eğitim Fakültesi, Ankara / Türkiye

\section{$\ddot{\mathbf{O z}}$}

Okullardaki başarıyı arttırmak için çalışanların psikolojik açıdan iyi, güçlü olmaları gerekir. Örgütsel bağlılık, çalışanların örgütün amaç ve değerleri yüksek düzeyde kabul etmesi ve inanması, örgütsel amaçları gerçekleştirmek için gayret sarf etmesi ve örgütte kalmak ve örgütsel üyeliği sürdürmek için duydukları arzudur. Örgütsel bağlılık, duygusal, devam ve normatif bağlılık alt boyutlarından oluşmaktadır. Örgütsel sinizm, örgütün bütünlükten ve dürüstlükten yoksun olma düşüncesi ve bireyin

\footnotetext{
${ }^{1}$ Bu çalışma 11-13 Eylül 2014 tarihlerinde Konya'da düzenlenen V. EYFOR'da (Eğitim Yönetimi Forumu) sözlü bildiri olarak sunulmuştur.

* Sorumlu Yazar. $\quad$ Tel: +90 5077612779

E-posta:alper_yorulmaz07@hotmail.com

(C) 2016 Kalem Eğitim ve Sağlık Hizmetleri Vakfı. Bütün Hakları Saklıdır. ISSN: 2146-5606
} 
örgütüne ilişkin olumsuz tutumudur. Örgütsel vatandaşlık davranışı, örgütün etkiliğini arttıracak her türlü davranışlardır. Buradan hareketle bu araştırmanın amacı, ilkokul öğretmenlerinin örgütsel bağl1lık, örgütsel sinizm ve örgütsel vatandaşlık davranışlarını algılamak ve aralarındaki ilişkiyi saptamaktır. Tarama modelinde gerçekleştiren araştırmanın evrenini İstanbul ili Bağcılar ilçesinde görev yapan sınıf öğretmenleri oluştururken, basit seçkisiz olarak seçilen 309 sınıf öğretmeni örneklemi oluşturmaktadır. Araştırma sonucunda, ilkokullarda görev yapan öğretmenlerin örgütsel bağl1lık ve örgütsel sinizm algıları orta düzeyde, örgütsel vatandaşlık davranışına ilişkin algı düzeyinin yüksek olduğu sonucuna ulaşılmıştır. Ayrıca, ilkokullarda görev yapan sınıf öğretmenlerinin örgütsel bağlılık ile örgütsel vatandaşlık davranışı algıları arasında pozitif ilişki, örgütsel sinizm ile örgütsel bağlılık ve örgütsel vatandaşlık davranışı arasında negatif ilişki bulunmuştur.

Anahtar Kelimeler: İlkokul; Öğretmen; Bağlılık; Sinizm; Vatandaşlık.

\title{
Relationship Between Organizational Commitment, \\ Cynicism And Citizenship Behaviors Of Elementary School Teachers
}

\begin{abstract}
In order to be able to improve the achievement at schools, workers of schools should be psychologically healthy and strong. Organizational commitment can be defined as acceptance of the organization's goals and values by its workers to a great extent, investment of efforts for the attainment of organizational goals and desire to remain in the organization and to maintain organizational membership. Organizational commitment is comprised of affective, continuation and normative commitment sub-dimensions. Organizational cynicism is the belief that the organization lacks unity and honesty and is the negative attitude of an individual towards his/her organization. Organizational citizenship behavior includes everything to be done to enhance the efficiency of the organization. Thus, the purpose of the current study was set to be to determine the relationship between organizational commitment, cynicism and citizenship behaviors of elementary school teachers. The universe of the present study employing the survey model is comprised of classroom teachers working in Bağcılar province of İstanbul and 309
\end{abstract}


classroom teachers selected from among the universe through the simple random sampling method make up the sampling of the study. At the end of the study, it was concluded that the participating teachers' organizational commitment and cynicism perceptions are at the medium level and their perceptions of organizational citizenship behavior are at the high level. Moreover, it was found that there is a positive relationship between the teachers' organizational commitment and organizational citizenship behavior perceptions and there is a negative relationship between organizational cynicism and organizational commitment and organizational citizenship behavior.

Keywords: Elementary school; Teacher; Commitment; Cynicism; Citizenship.

\section{Extended Summary}

\section{Purpose}

Within an era in which technology is rapidly advancing, the importance of education has been increasing and it is known that current research will make important contributions to future development. The achievement of education depends on schools and provision of quality education at schools depends on many factors as well as the existence of organizational norms. Psychological structure of educational organization is of great importance for the proper construction and functioning of organizational norms. The elements most profoundly affecting the psychological structure of educational organizations are organizational commitment, organizational cynicism and organizational citizenship. In this connection, it seems to be necessary to investigate organizational commitment, organizational citizenship behavior and organizational cynicism behavior of teachers working at schools that are the most important educational organizations and their relationship. Through such investigations, the cooperation between educational organizations is expected to increase and their performance 
will improve. Thus, the purpose of the current study was set to be to determine the relationship between elementary school teachers' organizational commitment, organizational citizenship behavior and organizational cynicism. For this purpose, the current study seeks answers to the following research questions:

1. What are the elementary school teachers' perceptions of organizational commitment, organizational cynicism and organizational citizenship behavior?

2. What is the relationship between the elementary school teachers' organizational commitment, organizational cynicism and organizational citizenship behavior?

\section{Method}

Relational survey model was employed in the current study. The universe of the study consists of 1276 classroom teachers working at elementary schools located in Bağcilar province of İstanbul in the spring term of 2013-2014 school year. A total of 309 teachers selected through simple random sampling method from among the teachers in the universe constitute the sampling of the current study. The research data were collected by using "Organizational Commitment Scale" adapted to Turkish by Boylu, Pelit and Güçer (2007), “Organizational Cynicism Scale" adapted to Turkish by Güzeller and Kalağan (2008) and "Organizational Citizenship Scale" adapted to Turkish by Taşdan and Yilmaz (2008). Frequencies and percentages were calculated for the demographic features of the participants. The variables underwent correlation analysis and thus the relationship between the variables was 
elicited. While interpreting the data to find answers to the research questions, the intervals were set to be "4.20-5.00" very high, “3.40-4.19” high, "2.60-3.39" medium, "1.80- 2.59" low and “1.00-1.79" very low.

\section{Results}

The classroom teachers' perception of organizational commitment is at the medium level $(\overline{\mathrm{X}}=2.94, \mathrm{~S}=.68)$. The sub-dimensions of organizational commitment, "Affective Commitment" ( $\bar{x}=3.02$, $\mathrm{S}=.93$ ) perception, "Continuation Commitment" ( $\overline{\mathrm{x}}=2.84, \mathrm{~S}=.87)$ perception and "Normative Commitment" $(\bar{x}=2.97, S=.94)$ perception are at the medium level. The classroom teachers' organizational cynicism perception $(\overline{\mathrm{X}}=2.79, \mathrm{~S}=.56)$ is at the medium level and their perception of organizational citizenship behavior $(\bar{X}=3.41, S=.66)$ is at the high level.

There is a negative relationship between the elementary school teachers' organizational commitment and organizational cynicism perceptions $(\mathrm{r}=-0.01, p<.01)$. A negative relationship was also found between the teachers' organizational cynicism and organizational citizenship behavior perceptions $(\mathrm{r}=-0.04, p<.01)$. A positive relationship was found between the teachers' organizational commitment and organizational citizenship behavior perceptions $(\mathrm{r}=0.19, p<.01)$.

\section{Discussion}

The elementary school teachers' organizational commitment perception is at the medium level. This finding of the current study is 
similar to those reported by Uygur and Yildirım (2011). Low level of teachers' organizational commitment might lead to decreasing student achievement. Therefore, teachers' organizational commitment should be enhanced to increase student achievement and to educate more qualified students.

The elementary school teachers' organizational cynicism perception is at the medium level. This finding concurs with the finding of Arslan (2012). For teachers to achieve their educational goals, their organizational cynicism perception should be reduced because high level of organizational cynicism results in teachers' developing negative attitudes towards their organizations.

The elementary school teachers' perception of organizational citizenship behavior is at the high level. This finding is parallel to the finding reported by Oğuz (2011). As the organizational commitment and devotion of the teachers will improve when their organizational citizenship behaviors improve, performance of their schools will be positively affected. Thus, it can be argued that teachers' organizational citizenship behaviors should be promoted.

It was found that there is a negative relationship between the teachers' organizational commitment levels and their organizational cynicism perceptions. This finding concurs with the finding of Y1ldiz (2013). It seems to be clear that to promote organizational commitment, the level of organizational cynicism should be reduced; thus, the school can better achieve its goals and improves its performance. A significant 
positive relationship was found between organizational commitment and organizational citizenship behavior. In this regard, it can be argued that when teachers' organizational citizenship behaviors are improved at schools, their commitment to their organizations will increase and organizational commitment of teachers not feeling like a citizen of the school will decrease.

When the relationship between organizational cynicism and organizational citizenship behavior was examined, a negative relationship was found between them. Thus, it can be claimed that improving organizational citizenship behavior leads to decreasing organizational cynicism and decreasing organizational cynicism makes contribution to the development of organizational citizenship behavior. These findings concur with the findings of İçerli and Yıldırım (2012).

\section{Conclusion}

The findings of the study revealed that the elementary school teachers' organizational commitment and organizational cynicism perceptions are at the medium level and their perception of organizational citizenship behavior is at the high level. It was also found that there is a positive relationship between the elementary school teachers' organizational commitment and organizational citizenship behavior perceptions and there is a negative relationship between their organizational cynicism and organizational citizenship behavior. With increasing level of organizational commitment, the teachers' organizational cynicism decreases and with increasing level of organizational citizenship behavior, the level of organizational cynicism decreases. 


\section{Giriş}

Teknolojinin hızla geliştiği, bilgi çağını yaşadığımız bu dönemde eğitimin önemi artmakta ve bu alanda yapılan çalışmaların geleceğe yapılan yatırımda, önemli olduğu bilinmektedir. Eğitimin başarılı olması okullara, okulların kaliteli eğitim sunması ise birçok faktörle birlikte okulun örgütsel normların üzerine kurulması ile gerçekleşmektedir. Bundan dolayı okulların örgütsel normlarını sağlamak için örgüt kuramcıları örgüte dâir adalet, güven, bağl1lık, kültür, sinizm, güç ve vatandaşlık gibi kavramları ortaya çıkarmışlardır. Alanyazın incelendiğinde örgütsel bağl1lık ile örgütsel sinizm ve örgütsel vatandaşl1k davranışı, örgütsel sinizm ile örgütsel vatandaşlık davranışına ilişkin çalışmalar bulunmaktadır (Arslan, 2012; Baş ve Şentürk, 2011; Boylu, Pelit ve Güçer, 2007; Buluç, 2009; Doğan-K1lıç, 2013; Erdem, 2010; Helvacı ve Çetin, 2012; Kalağan ve Güzeller, 2010; Korkmaz, 2011; Koşar ve Yalçınkaya, 2013; Kurşunoğlu, Bakay ve Tanrı̈ğen, 2010; Polat ve Celep, 2008; Sezgin, 2005, 2010; Y1ldı, 2013; Yörük ve Sağban, 2012). Ancak örgütsel bağl1lık, örgütsel sinizm ve örgütsel vatandaşlık davranışı ilişkisini belirten çalışmaların olmaması bu çalışmanın önemini arttırmaktadır. Çünkü örgütsel bağlılığın ve örgütsel vatandaşlığın artması örgütün aktivitesini arttırırken, örgütsel sinizm örgütü olumsuz yönde etkileyerek örgütün performansında düşmeye sebep olduğu düşünülmektedir. Eğitim örgütlerinin performanslarını arttırmak için örgütsel bağlılık, örgütsel sinizm ve örgütsel vatandaşlık kavramları arasındaki ilişkiyi ortaya koymak önemlidir. Bundan dolayı bu alanda ilişkileri saptayacak ve öneriler ortaya koyacak çalışmalara ihtiyaç bulunmaktadır. 


\section{Örgütsel Bağlılık}

Örgütsel bağl1lık, örgütün amaç ve değerlerini yüksek düzeyde kabul etme ve inanma, örgüt için çaba göstermeye istekli olma ve örgütte üyeliği sürdürmek için duydukları arzu olarak tanımlanmaktadır (Allen ve Meyer, 1990; Morrow, 1983). Örgütsel bağl1lığ1, işgörenin örgüte sadakatle bağl1lığına, kendini örgütle özdeşleştirmesine ve örgütte kalıcı olmasına yönelik eğilimi ya da isteği olarak görmektedir. Çalışanlar, kendilerini örgütlere bağlı oldukları ölçüde başarı sağlarlar ve yetenek ve bilgilerini örgüt için kullanırlar. Örgütsel bağl1lık genel olarak çalışanların örgütle bütünleşme ve değerleri benimseme derecesine ve örgüt üyesi olarak kalma istekliliğini ifade etmektedir (Blau ve Boal, 1987). Meyer ve Allen'in (1991) yaptıkları araştırmalar sonucunda örgütsel bağl1lığ duygusal bağlılık, devam bağl1lığ 1 ve normatif bağl1lık olmak üzere üç boyutu olan “Örgütsel Bağlılık Modeli”ni geliştirmişlerdir. Duygusal bağhllık, işletmede çalışan bireylerin duygusal olarak kendi tercihleri ile işletmede kalma arzusu, devam bağlllığı çalışanların örgütten ayrılmalarının işletmeye getireceği maliyeti ve olumsuzlukları dikkate alması, bir zorunluluk olarak işletmeye devam etmesi ve normatif bağglılık çalışanların ahlâkî bir görev duygusuyla ve işletmeden ayrılmamanın gereğine inandıkları için kendilerini örgüte bağlı hissetmeleridir.

Örgütsel bağlılı̆̆ oluşturan üç boyutta da bireylerin örgüt içinde devam etme isteklerinin esas unsur olduğu ortaya çıkmaktadır (Özdevecioğlu, 2003). Ancak bu boyutlar arasında örgüte bağlılık; isteğe, gereksinime ve yükümlülüğe dayanmaktadır (Obeng ve Ugboro, 2003). 
Alanyazında çalışanlarda öncelikle yüksek duygusal bağl1lık, sonra normatif bağl1lık ve en son olarak devam bağglığının olması gerektiği tespit edilmiştir (Brown, 2003).

Örgütsel bağlılık, verimi ve kaliteyi arttırır, uygulanabilir yenilikleri ortaya çıkarır (Çetin, 2004). Bu durumu okul örgütlerine uyguladığımızda öğretmenlerin okula olan bağlılıkları akademik performans düzeylerinin belirleyicisi olmaktadır. Tsui ve Cheng (1999) de öğretmenlerin örgütsel bağlılığını, kendilerini çalıştıkları okul ile güçlü şekilde özdeşleştirmeleri ve okula dâhil olmaları biçiminde ifade etmektedir. Buna göre öğretmenlerin örgütsel bağlılı̆̆ı; okulun amaçlarına ve değerlerine güçlü şekilde inanma ve bunları kabul etme, okul adına önemli düzeyde çaba göstermeye istekli olma ve okulun bir üyesi olmayı ya da okulda çalışmayı sürdürmeye yönelik güçlü bir istek gösterme şeklinde düşünülebilir.

\section{Örgütsel Sinizm}

Sinizm, bireysel ya da örgütsel özelliklerden kaynaklanmaktadır. $\mathrm{Bu}$ doğrultuda karşımıza örgütsel sinizm kavramı çıkmaktadır. Bireyin örgüte karşı geliştirdiği olumsuz tutumu ifade eden örgütsel sinizmin üç boyutu bulunmaktadır. Bunlar (Dean, Brandes ve Dharwadkar, 1998):

1. Örgütün dürüstlükten yoksun olduğuna dâir inanç,

2. Örgüte yönelik negatif bir duygu,

3. Bu inançlar ve duygulara uygun örgüte yönelik aşağllayıcı ve eleştirel davranma eğilimidir. 
Örgütsel sinizmin bilişsel boyutunda sinik bireyler; örgütün adalet, dürüstlük ve samimiyet gibi prensiplerden yoksun olduğuna ve bu ilkelerin kişisel çıkarlar uğruna kurban edilebileceğine inanır. Örgütsel sinizmin ikinci boyutu duyuşsal boyut olarak ele alınmıştır. Burada sinik tutumları kavramlaştırmayı önemli olan dokuz temel duyguya dayandırmışlardır. Bunlar; ilgi-heyecan, zevk-neşe, sürpriz-şaşkınlık, acı-1stırap, kızgınlık-öfke, tiksinme-nefret, hor görme-küçümseme, korku-dehşet, utanç-aşağılanmadır (Dean vd., 1998). Örgütsel sinizmin üçüncü boyutu ise, davranışsal boyuttur. Bu boyut, sinik tutumun belli davranış tiplerine yönelik eğilimlerini içermektedir (Dean vd., 1998). Davranışsal boyutta, sinik tutuma sâhip çalışanlar örgütlerini eleştirmektedir (Arslan, 2012). Örgütlerin çoğunda sinik davranışlar sergileyen iş görenler yer almaktadır (James, 2005). Bu anlamda eğitim örgütlerinde çalışan iş görenlerin sinizm yaşama eğilimlerini de göz ardı etmemek gerekir. Vance, Brooks ve Tesluk (1997) bireylerde, "çalıştıkları kurumların daha iyiye gidebileceği yalnız bu ihtimalin oldukça düşük olduğu inancı"nın var olmasının örgütsel sinizmin oluşmasına neden olduğunu belirtmiştir (akt; Stanley, 1998). Bu anlamda, örgütsel sinizm yaşayan bir öğretmen:

1. Okulunu geliştirmek için girişimlerde bulunmanın, diğer çalışanlar tarafından önemsenmediği duygusuna kapılabilir.

2. Okulunu geliştirmek için önerilerde bulunmayı bırakabilir.

3. Okulundaki kaliteyi artırmak için sunduğu önerilerin dikkate alınmadığını düşünebilir. 
4. Okulunu geliştirmek için yaptığı çabaların bilinmediği düşüncesi var olabilir.

5. Bütün öğretmenlerin, çalıştıkları okulu geliştirmek için ellerinden gelen çabayı sarf edeceklerine inanmayabilir.

6. Yapılan uygulamalar sonucunda herkese âdil davranılmayacağını ve böylelikle hak etmeyen bir kişinin ya da davranışın itibar göreceğini düşünülebilir.

7. İşlerin daha iyiye gideceğine inanmayabilir.

8. Okulunun geleceği ile ilgili umutlu olması zor olabilir.

\section{Örgütsel Vatandaşlık Davranışı}

Örgütsel vatandaşlık kavramını Organ (1988), “isteğe bağlı davranışlar arasında, biçimsel ödüllendirme sistemi içerisinde doğrudan ve açık bir şekilde yer almayan, örgütsel işlevleri arttırmaya yönelik olan bireysel davranışlar olarak tanımlamaktadır. Örgütsel vatandaşlık kavramı, örgüt açısından istenilen, arzulanılan etkinliğe ulaşılmak adına sergilenen davranışlardır. Örgütsel vatandaşlık, davranış kalıpları içerisinde iş arkadaşlarına yardımcı olma, işin ve mesleğin geliştirilmesi sürecine olumlu katkıda bulunma, zamana uyum sağlama gibi, aslında iş tanımlarında yer almayan işin geneli içinde yer alan davranışlar mevcuttur. Bununla birlikte örgütsel vatandaşlık kavramına yönelik örneklerin ortak noktası gönüllüktür (Sezgin, 2005).

Örgütsel vatandaşlık davranışı kavramı ile ilgili yapılan çalışmalarda pek çok boyuttan söz edilmektedir. Ancak Organ (1988) örgütsel vatandaşlık kavramını sivil erdem, özgecilik, vicdan sâhibi olma, sportmenlik ve nezaket olmak üzere beş farklı boyutta ifade etmiştir. 
Organ'in (1988) aksine DiPaola, Tarter ve Hoy (2005), örgütsel vatandaşlık davranışının genel bir davranış boyutu olduğunu belirtmektedir. Bu anlamda, DiPaola vd. (2005), örgütsel vatandaşlık davranışının boyutlarla ifade edilemeyeceğini, aksine örgütsel vatandaşlık davranışını tek bir boyutta ele almanın doğru olacağını vurgulamaktadır.

Örgütsel bağlılık, örgütsel sinizm ve örgütsel vatandaşl1k davranışı örgüt çalışanları üzerinde etkili olup örgütlerin psikolojik yapılarını etkilemektedir. Bu etki olumlu olup örgüte ivme kazandıracağı gibi olumsuz olup örgütü işlevsiz hale de getirebilir. $\mathrm{Bu}$ doğrultuda, bu yapılardan örgütsel bağl1lık ve örgütsel sinizm arasında negatif bir ilişki vardır (Abraham, 2000). Örgütsel sinizm ve örgütsel bağlılık birbirlerinden farklı kavramlar olmakla birlikte örgütsel sinizm örgütsel bağlılık eksikliğinden daha güçlü bir duyguyu ifade etmektedir (Kalağan, 2009). Örgütsel bağl1lık ile örgütsel vatandaşlık davranışı konusunda yapılan çalışmalar incelendiğinde, örgütsel vatandaşlık davranışının öncüllerinden birinin örgütsel bağlılık olduğu varsayılmaktadır (Schappe, 1998). Örgütsel sinizm inceleyen çoğu araştırmada sinizm bireysel ve örgütsel etkinlik üzerinde negatif yönlü önemli ve sürekli bir etkisinin olduğu öne sürülmektedir. Örgütsel sinizm; örgütsel vatandaşlık davranışı, iş tatmini, örgütsel bağlılık, motivasyon ve değişim yaratma niyetini azaltmakla ilişkilendirilmektedir (Özler, Atalay ve Şahin, 2010). Bundan dolayı özellikle eğitim örgütleri olan okullarda görev yapan öğretmenlerin örgütsel bağlılık, örgütsel vatandaşlık davranışı ve örgütsel sinizm davranışlarının araştırılmasına ve ilişkilendirilmesine gerek duyulmaktadır. Buradan hareketle bu çalış- 
mada ilkokul öğretmenlerinin sergiledikleri örgütsel bağlılık, örgütsel vatandaşlık davranışı ve örgütsel sinizmleri arasındaki ilişkinin belirlenmesi amaçlanmıştır. Bu bağlamda araştırmanın alt amaçları şunlardir:

1. İlkokul öğretmenlerinin örgütsel bağlılık, örgütsel sinizm ve örgütsel vatandaşlık davranışına ilişkin algıları nasıldır?

2. İlkokul öğretmenlerinin örgütsel bağl1lık, örgütsel sinizm ve örgütsel vatandaşlık davranışları arasında ilişki nedir?

\section{Yöntem}

\section{Araştırmanın Modeli}

$\mathrm{Bu}$ araştırmada ilkokullarda görev yapan sınıf öğretmenlerinin örgütsel bağlılık algıları ile örgütsel sinizm ve örgütsel vatandaşlık davranışı arasındaki ilişki saptamak için ilişkisel tarama modeli kullanılmıştır.

\section{Evren ve Örneklem}

Araştırmanın evrenini 2013-2014 eğitim öğretim yılı bahar döneminde İstanbul ili Bağcılar ilçesinde resmî ilkokullarda görev yapan 1276 sınıf öğretmeni oluşturmaktadır. Bu evrenden basit, seçkisiz örneklem yoluyla seçilen 309 sınıf öğretmeni araştırmaya katılmıştır. İlkokulda görev yapan öğretmenlerin demografik özelliklerine göre dağılımları Tablo 1'de verilmiştir. 
Tablo 1. Öğretmenlerin Demografik Özelliklerine Göre Dağılımı

\begin{tabular}{llll}
\hline & & f & \% \\
\hline Cinsiyet & Erkek & 136 & 44.0 \\
& Kadın & 173 & 56.0 \\
\hline Yaş & 21-30 yaş & 115 & 37.2 \\
& 31-40 yaş & 142 & 46.0 \\
& 41 yaş ve üstü & 52 & 16.8 \\
\hline Kidem & $1-10$ yıl & 177 & 57.3 \\
& $11-20$ yıl & 106 & 34.3 \\
& 21 yıl ve üstü & 26 & 8.4 \\
\hline Okuldaki & $1-5$ y1l & 189 & 61.2 \\
Hizmet Y111 & 6-10 y1l & 79 & 25.6 \\
& 11 y1l ve üstü & 41 & 13.2 \\
\hline TOPLAM & & 309 & 100.0 \\
\hline
\end{tabular}

Tablo 1 incelendiğinde ilkokullarda görev yapan öğretmenlerin \%44'ü erkek, \%56'sı kadındır. Öğretmenlerin yaşlarına göre dağılımında en fazla yı̆̆ılma \%46 ile "31-40 yaş” grubunda olmuştur. Öğretmenlerin yaş grubunda en az yığglma \%16.8 ile "41 yaş ve üstü” grubundadır. Öğretmenlerin kıdem grubunda en fazla yığılma \%57.3 ile "1-10 yıl”" grubunda, en az yığılma \%8.4 ile "21 y1l ve üstü" grubundadır. Öğretmenlerin okuldaki hizmet yılı grubunda en fazla y1ğ1ma \%61.2 ile “1-5 yıl” grubunda, en az yığılma \%13.2 ile "11 yıl ve üstü “ grubundadır.

\section{Verilerin Toplanması}

Araştırma verileri ölçekler ile toplanmıştır. Araştırma verileri öğretmenlerden Meyer ve Allen (1984) tarafından geliştirilen Boylu, Pelit ve Güçer (2007) tarafından Türkçeye uyarlanan “Örgütsel Bağl1lık Ölçeği”, Vance, Brooks ve Tesluk (1997) tarafından geliştirilmiş, 
Türkiye'de Güzeller ve Kalağan (2008) tarafından Türkçeye uyarlanan “Örgütsel Sinizm Ölçeği”, DiPaola ve ark. (2005) tarafından geliştirilmiş, Taşdan ve Yılmaz (2008) tarafından Türkçeye uyarlanan “Örgütsel Vatandaşlık Ölçeği” ile toplanmıştır. Araştırmada veri toplama aracı olarak kullanılan ölçekler daha önceden geliştiren kişiler tarafından geçerliliği ve güvenirliği sağlanmış ölçeklerdir. Ölçekler araştırmacı tarafından uygulanmıştır. Ölçekler uygulandıktan sonra araştırmacı tarafından elden toplanmıştır. Ölçek 330 öğretmene dağıtılmış, ölçeklerin 315'i geri dönmüştür. Ancak 6 ölçek hatalı doldurulmasından dolayı geçerli sayılmamış, analiz için 309 ölçek geçerli sayılmıştır.

\section{Veri Toplama Aracı}

Araştırmada veri toplamak için kullanılan ölçeklere ilişkin bilgiler aşağıda verilmiştir.

Örgütsel Bağlılık Ölçeği: Meyer ve Allen (1984) tarafindan geliştirilen ve Boylu, Pelit ve Güçer (2007) tarafından Türkçeye uyarlanan “Örgütsel Bağlılık Ölçeği”’inde yer alan 17 adet soru bulunmaktadır. Ölçek; duygusal bağl1lık, devam bağl1lı̆g ve normatif bağl1lık olmak üzere üç boyutu bulunmaktadır. Ölçekte öğretmenlerin duygusal bağlilıklarını $(1,2,3,4,5,6$. maddeler), devam bağlılıklarını $(7,8,9,10,11,12$. maddeler) ve normatif bağlılıklarını $(13,14,15,16,17$. maddeler) ölçmeye yönelik maddeler bulunmaktadır. Boylu, Pelit ve Güçer (2007) tarafından yapılan araştırmada ölçeğin duygusal bağlılık boyutuna ilişkin güvenirlik katsayısı Cronbach Alpha .92, devam bağlılığı boyutuna ilişkin güvenirlik katsayısı Cronbach Alpha .79 ve normatif bağl11ık boyutuna ilişkin güvenirlik katsayısı Cronbach Alpha .80 ola- 
rak verilmiştir. $\mathrm{Bu}$ araştırmada da ölçeğin bütün boyutlarına ilişkin güvenirlik katsayısı Cronbach Alpha .86'dır. Ölçeğin alt boyutlarından duygusal bağglılı boyutu .88 , devam bağlılığı boyutu .76 ve normatif bağlılık boyutuna ilişkin güvenirlik katsayısı Cronbach Alpha .81 olarak bulunmuştur.

Örgütsel Sinizm Ölçeği: Çalışanların örgüt içerisinde ne düzeyde sinizm ile karşı karşıya kaldıklarını ölçmek amacıyla Vance, Brooks ve Tesluk (1997) tarafından geliştirilmiştir. Ölçek, 6'sı olumlu, 3'ü olumsuz madde olmak üzere 9 maddeden oluşmaktadır. Ölçek, tek boyutludur. Ölçek geliştirme sürecinde, iç tutarlılık katsayısı .84 olarak belirlenmiştir (Vance, Brooks ve Tesluk, 1997'den akt; Kalağan ve Güzeller, 2010). Kalağan ve Güzeller (2010) tarafından Türkçeye uyarlanmıştır. Ölçeğin güvenirliğini belirlemek için hesaplanan Cronbach Alpha iç tutarlık katsayısı .83 olarak bulunmuştur. Bu araştırmada ise ölçeğin Cronbach Alpha güvenirlik katsayısı .71 olarak bulunmuştur.

Örgütsel Vatandaşlık Davranışı Ölçeği: DiPaola, Tarter ve Hoy (2005) tarafından geliştirilmiş, Taşdan ve Yılmaz (2008) tarafından Türkçeye uyarlanan tek boyutlu, 10'u olumlu, 2'si olumsuz olarak yazılmış likert tipi 12 maddeden oluşmaktadır. Türkçeye uyarlanarak geçerlilik ve güvenirlik çalışması yapılan ölçeğin güvenirlik analizleri sonucunda güvenirlik katsayısı .87 olarak belirlenmiştir. $\mathrm{Bu}$ araştırmada ise ölçeğin Cronbach Alpha iç tutarlılık katsayısı .83 olarak bulunmuştur. 


\section{Verilerin Analizi ve Çözümlenmesi}

Çalışma grubunda yer alan öğretmenlerin demografik özelliklerine ilişkin frekans ve yüzde dağılımlarına bakılmıştır. Araştırmada öğretmenlerin okullarına ilişkin örgütsel bağl1lık, örgütsel sinizm ve örgütsel vatandaşlık davranışı ve bunların alt boyutlarına ilişkin algıları saptamak için frekans, yüzde ve standart sapmalarının dağılımlarına bakılmıştır. Bütün değişkenler korelasyon analizine tâbi tutulmuş ve değişkenler arasındaki ilişkiler ortaya konulmuştur. İki değişken arasındaki korelasyon ilişkinin yönünü, kuvvetini belirtmede kullanılan korelasyon katsayılarının “+” ya da “_” olması ilişkinin yönünü belirlemede kullanılmıştır. Korelasyon katsayıları değerlendirilirken katsayılar, mutlak değer olarak 0.70 ile 1.00 arasında ise "yüksek", 0.69 ile 0.30 arasında ise "orta", 0.29 ve daha düşükse değerde ise "düşük" düzeyle ilişkili olarak ve 0.00 yaklaştıkça ise ilişki olmadığ 1 şeklinde yorumlanmıştır (Büyüköztürk, Kılıç-Çakmak, Akgün, Karadeniz ve Demirel, 2010). Araştırmada alt problemlerin çözümlenmesine dönük olarak elde edilen bulgular yorumlanırken; aralıklar " $4.20-5.00$ " çok yüksek, “3.40-4.19” yüksek, “2.60-3.39” orta, “1.80-2.59” düşük ve “1.00-1.79” çok düşük olarak değerlendirilmiştir.

\section{Bulgular}

Araştırmada ilkokullarda görev yapan öğretmenlerin örgütsel bağlılık, örgütsel sinizm ve örgütsel vatandaşlık davranışına ilişkin bulguları başlıklar altında verilmiştir. 
Tablo 2. İlkokul Öğretmenlerinin Örgütsel Bağll1ık, Örgütsel Sinizm ve Örgütsel Vatandaşlık Davranışına İlişkin Algııarına Âit Ortalama ve Standart Sapma Değerleri

\begin{tabular}{lccc}
\hline & $\mathbf{N}$ & $\overline{\mathrm{X}}$ & $\mathbf{s S}$ \\
\hline Örgütsel Bağlılık & 309 & 2.94 & .68 \\
Duygusal Bağl1lık & 309 & 3.02 & .93 \\
Devam Bağlılığı & 309 & 2.84 & .87 \\
Normatif Bağlılık & 309 & 2.97 & .94 \\
Örgütsel Sinizm & 309 & 2.79 & .56 \\
Örgütsel Vatandaşlık Davranışı & 309 & 3.41 & .66 \\
\hline
\end{tabular}

Tablo 2'de ilkokullarda görev yapan öğretmenlerin örgütsel bağlılık ve alt boyutları ile örgütsel sinizm ve örgütsel vatandaşlık davranışına ilişkin aritmetik ortalamalar ve standart sapmalar verilmiştir. Genel olarak öğretmenlerin okullarına ilişkin bağlılık algıları ( $\overline{\mathrm{X}}=2.94$, ss=.68) "Orta” düzeydedir. Örgütsel bağl1lı̆̆ın alt boyutlarından "Duygusal Bağlılık" ( $\overline{\mathrm{X}}=3.02$, ss=.93) algıları, "Devam Bağl1lığı" ( $\overline{\mathrm{X}}=2.84, \mathrm{ss}=.87)$ algiları ve "Normatif Bağl1lık" $(\overline{\mathrm{X}}=2.97, \mathrm{ss}=.94)$ algıları "Orta" düzeydedir. İlkokullarda görev yapan öğretmenlerin örgütsel sinizm algıları ( $\overline{\mathrm{X}}=2.79, \mathrm{ss}=.56)$ "Orta”, örgütsel vatandaşl1k davranışına ilişkin algıları ise ( $\overline{\mathrm{x}}=3.41$, ss=.66) "Yüksek" düzeydedir.

Tablo 3'te, ilkokul öğretmenlerinin örgütsel bağl1lık ile örgütsel sinizm algıları arasında düşük düzeyde negatif yönde bir ilişki ( $\mathrm{r}=-0.01$, $p<.01)$ olduğu sonucuna ulaşılmıştır. İlkokul öğretmenlerin örgütsel bağlılık düzeyleri arttıkça örgütsel sinizm algıları o oranda azalmaktadır. Yine öğretmenlerin örgütsel sinizm ile örgütsel vatandaşlık davranışı algıları arasında düşük düzeyde negatif yönde bir ilişki ( $r=-0.04$, 
$p<.01)$ bulunmuştur. Öğretmenlerin örgütsel vatandaşl1k davranış1 düzeyleri arttıkça örgütsel sinizm davranışı azalmaktadır. İlkokullarda görev yapan öğretmenlerin örgütsel bağlılık ile örgütsel vatandaşlık davranışı algıları arasında düşük düzeyde pozitif yönde bir ilişki $(\mathrm{r}=0.19, p<.01)$ ortaya çıkmıştır. Öğretmenlerin örgütsel bağl1lık düzeyleri arttıkça örgütsel vatandaşlık davranışı algıları da artmaktadır.

Tablo 3. İlkokul Öğretmenlerinin Örgütsel Bağlılık, Örgütsel Sinizm ve Örgütsel Vatandaşılık Davranışı Algıları Arasındaki İlişki

\begin{tabular}{|c|c|c|c|c|c|c|}
\hline & 1 & 2 & 3 & 4 & 5 & 6 \\
\hline Örgütsel Bağlılık (1) & 1 & & & & & \\
\hline Duygusal Bağl1lık (2) & $.76^{* *}$ & 1 & & & & \\
\hline Devam Bağl1lı̆̆ (3) & $.68^{* *}$ & $.19^{* *}$ & 1 & & & \\
\hline Normatif Bağlılık (4) & $.79^{* *}$ & $.49^{* *}$ & $.35^{* *}$ & 1 & & \\
\hline Örgütsel Sinizm (5) & $-.01^{* *}$ & $-.11^{* *}$ & $.09^{* *}$ & $-.01^{* *}$ & 1 & \\
\hline $\begin{array}{l}\text { Örgütsel Vatandaşlık } \\
\text { Davranışı (6) }\end{array}$ & $.19^{* *}$ & $.27^{* *}$ & $.07^{* *}$ & $.07^{* *}$ & $-.04^{* *}$ & 1 \\
\hline
\end{tabular}

Örgütsel bağlılık ölçeğinin alt boyutlarında "duygusal bağlılık" ile "devam bağlılı̆ğ” arasında $(\mathrm{r}=0.19, p<.01)$ düşük düzeyde pozitif bir ilişki bulunmaktadır. Duygusal bağlılık arttıkça devam bağlılı̆̆1 artmaktadır. "Normatif bağlılık" ile "duygusal bağlılık" arasında orta düzeyde pozitif bir ilişki $(\mathrm{r}=0.49, p<.01)$ bulunmaktadır. Duygusal bağlılık arttıkça normatif bağlılık artmaktadır. "Duygusal bağlılık" ile “örgütsel sinizm” arasında düşük düzeyde negatif yönde bir ilişki ( $\mathrm{r}=-0.11, p<.01)$ bulunmaktadır. Duygusal bağlılık arttıkça örgütsel sinizm davranışı azalmaktadır. "Duygusal bağlılık” ile “örgütsel vatandaşlık davranışı" arasında düşük düzeyde pozitif yönde bir ilişki 
$(\mathrm{r}=0.27, p<.01)$ bulunmaktadır. Duygusal bağlılık davranışı arttıkça örgütsel vatandaşlık davranışı artmaktadır.

Örgütsel Bağl1lık ölçeğinin alt boyutlarından "devam bağlılı̆̆ı” ile "normatif bağl1lık" arasında $(\mathrm{r}=0.35, p<.01)$ orta düzeyde pozitif bir ilişki bulunmaktadır. Devam bağlılığı arttıkça normatif bağlılık artmaktadır. "Devam bağlılığı" ile "örgütsel sinizm" $(\mathrm{r}=0.09, p<.01)$ ve "Örgütsel vatandaşlık davranış1” (r=0.07, $p<.01)$ arasında düşük düzeyde pozitif bir ilişki bulunmaktadır. Devam bağlılığı arttıkça örgütsel sinizm ve örgütsel vatandaşlık davranışı artmaktadır.

Örgütsel bağlılık ölçeğinin alt boyutlarından "normatif bağlılık" ile "örgütsel sinizm” arasında $(\mathrm{r}=-0.01, p<.01)$ düşük düzeyde negatif bir ilişki bulunmaktadır. "normatif bağlılık" ile "örgütsel vatandaşlık davranışı" arasında ( $\mathrm{r}=0.07, p<.01)$ düşük düzeyde pozitif bir ilişki bulunmaktadır. Normatif bağlılık arttıkça örgütsel vatandaşlık davranışı artmaktadır.

“Örgütsel bağl1l1k” ile “duygusal bağl1l1k” $(\mathrm{r}=0.76, p<.01)$ ve "normatif bağlılık" (r=0.79, $p<.01)$ arasında yüksek düzeyde pozitif yönde bir ilişki bulunmaktadır. Duygusal bağlılık ve normatif bağlılık arttıkça örgütsel bağlılık artmaktadır. "Örgütsel bağl1lık” ile "devam bağlılığı” arasında orta düzeyde pozitif yönde bir ilişki $(\mathrm{r}=0.68, p<.01)$ bulunmaktadır. Devam bağlılığı arttıkça örgütsel bağlılık artmaktadır. 


\section{Tartışma ve Sonuç}

$\mathrm{Bu}$ araştırmada, ilkokullarda görev yapan öğretmenlerin örgütsel bağlılık, örgütsel sinizm ve örgütsel vatandaşlık davranışı algıları arasındaki ilişki incelenmiştir.

İlkokullarda görev yapan öğretmenlerin örgütsel bağl1lık algıları orta düzeydedir. Araştırma sonuçları Akyol, Atan ve Gökmen (2013), Özgan, Külekçi ve Özkan (2011), Uygur ve Yıldırım (2011) tarafından yapılan araştırma sonuçları ile benzerlik göstermektedir. Ancak, Boylu, Pelit ve Güçer (2007), Buluç (2009), Erdem (2010), Korkmaz (2011)

ve Yıldız'ın (2013) çalışmaları ile benzerlik göstermemektedir. Öğretmenlerin örgütsel bağlılıklarının düşük olması öğrenci başarısını azaltmaktadır. Bundan dolayı öğrenci başarısını arttırmak, daha nitelikli öğrenci yetiştirmek için öğretmenlerin örgütsel bağlılıklarının arttırılması gerekmektedir. Bundan dolayı bağlılığı oluşturan duygusal, devam ve normatif bağlılık boyutlarının etkili bir şekilde kullanılmasına gereksinim vardır. Çünkü okullarına, öğrencilerine ve çalışma alanlarına güçlü şekilde yönelim gösteren öğretmenlerde yüksek düzeyde bağlılık ortaya çıkacaktır. Etkili bir bağlanmanın gerçekleşmesi için öğretmenlerin içten bağlanmalarına gerek duyulmaktadır. Tükenmiş, iş yapmaktan kaçan, iletişim yolları zayıflamış öğretmenlerin bulunduğu okullarda bağlılık düşük olacağından başarının olması imkânsızdır. Bundan dolayı örgütsel bağlılık orta düzeyden alınarak yüksek düzeye çıkarılmaya çalışılmalıdır.

Araştırmaya katılan sınıf öğretmenlerinin örgütsel bağlılığın alt boyutlarına ilişkin duygusal bağlılık, devam bağlılığı ve normatif bağ- 
111ık algıları orta düzeydedir. Örgütsel bağlılığın alt boyutlarından olan duygusal bağlılık, devam bağlılığı ve normatif bağl11ıklarının öğretmenlerde ne düzeyde olduğunu belirlemek için yapılan istatistik sonucunda öğretmenlerin duygusal bağl1lıklarının daha yüksek olduğu bunu normatif bağl1lık ve devam bağlılığı izlediği sonucuna ulaşılmıştır. Bu bulgu Akyol, Atan ve Gökmen (2013) ve Y1ldız (2013) tarafından yapılan araştırmalar ile benzerlik göstermektedir. Okula karşı yüksek derecede duygusal bağl1lık gösteren öğretmenler okulları ile özdeşleşmektedir. Buna bağlı olarak da okulun amaçlarını kendi amaçları olarak görecek, okuldaki sorunları çözmek için yüksek performans sergileyecek, yoğun çaba göstereceklerdir. Duygusal bağglılı̆̆1 düşük olan öğretmenler ise kendi amaçları ile okulun amaçlarını ayrı tutacaklar, değişime ve başarıya yönelik bir inanç taşımadıkları için çaba göstermeyeceklerdir. Öğretmenler okullarına karşı yüksek düzeyde devam bağlılığını göstermeleri onların maddî bir amaç için okulda çalıştıklarını ortaya koymaktadır. Okula karşı yüksek düzeyde normatif bağlılık gösteren öğretmen ise öğrenci başarılarını arttırma yönünde üst düzeyde bir gayret içinde olacak, derslerini ahlâkî sorumlulukları doğrultusunda eksiksiz yürütmeye çalışacağı söylenebilir. Buradan hareketle okulların başarısının artması, amaçlarına ulaşması için öğretmenlerin duygusal bağlılık ve normatif bağl1lıklarının yüksek düzeyde olmasına, devam bağlılığının ise yüksek olmamasına dikkat edilmesi gerektiği söylenebilir.

İlkokul öğretmenlerinin örgütsel sinizm algıları orta düzeydedir. $\mathrm{Bu}$ sonuç Arslan (2012) tarafindan yapılan araştırma sonuçları ile pa- 
ralellik göstermektedir. Ancak, Kalağan ve Güzeller (2010) tarafından yapılan çalışmalar ile benzerlik göstermemektedir. Okullarda öğretmenlerin başarısı, amaçlarına ulaşması için örgütsel sinizm algılarının düşük olmasına gerek duyulmaktadır. Çünkü örgütsel sinizm algısının yüksek olması okul örgütlerinde bulunan öğretmenlerin negatif tutum sergilemesine, kalite ve verimin düşmesine, okulu geliştirecek önerilerden kaçınmaya, âdil davranılmayacağına, görevi lâyık olan kişiye verilmeyeceği düşüncesine sâhip olacağı inancını ortaya çıkaracaktır. $\mathrm{Bu}$ durum da okulda görev yapan öğretmenlerin okuldan uzaklaşması, motivasyonun düşmesi ve verimin azalmasına sebep olacağı düşünülebilir.

İlkokul öğretmenlerinin örgütsel vatandaşl1k davranışına ilişkin algıları yüksek düzeydedir. Bu sonuç Oğuz (2011) ile benzerlik göstermektedir. Ancak, Buluç (2008), Baş ve Şentürk (2011) yaptığ1 çalışmalar ile benzerlik göstermemektedir. Örgütsel vatandaşlık davranışı artan öğretmenlerin okula olan bağlılıkları, adanmışlıkları artacağından okulun performansı artacaktır. Örgütsel vatandaşlık davranışı, isteğe bağlı, ödüllendirmenin olmadığı, örgütsel işlevleri arttırmaya yönelik davranışların bulunduğu, örgüt içerisinde istenilen davranışa ulaşılmak için kullanılan etkinliklerdir. Örgütsel vatandaşlığın yüksek olduğu okullarda örgüt yıkıcı ve istenmeyen davranışlar ortadan kalkacak, yetenek ve becerilerini ortaya koyacak, etkin bir koordinasyon sağlanacaktır. Bundan dolayı okullarda yer alan öğretmenlerin örgütsel vatandaşlığı arttırıcı vicdan, erdem, nezâket, sportmenlik ve gönüllülük 
esasına dayalı bir şekilde harekete geçirilmelerine gerek duyulduğu söylenebilir.

Araştırma sonucunda ilkokullarda görev yapan sınıf öğretmenlerinin örgütsel bağlılık ile örgütsel vatandaşlık davranışı algıları arasında pozitif ilişki, örgütsel sinizm ile örgütsel bağl1lık ve örgütsel vatandaşlık davranışı arasında negatif ilişki bulunmuştur. Öğretmenlerin örgütsel bağlılık algıları arttıkça örgütsel vatandaşlı̆̆ı arttığı, örgütsel sinizmin azaldığg sonucuna ulaşılmıştır. Örgütsel vatandaşlık davranışı arttıkça örgütsel sinizmin azaldığı ortaya çıkmıştır.

Örgütsel bağl1lık ile örgütsel sinizm davranışı incelendiğinde aralarında güçlü ve anlamlı bir ilişkinin olduğu ortaya çıkmıştır. Öğretmenlerin örgütsel bağlılık düzeyleri ile örgütsel sinizm algıları arasında negatif yönde bir ilişkinin olduğu sonucuna ulaşılmıştır. Alanyazın incelendiğinde, Özgan, Külekçi ve Özkan (2011), Yıldız (2013) ile araştırma sonucu benzerlik göstermektedir. Örgütsel bağlılığı arttırmak için örgütsel sinizm davranışının azaltılması okulun verimliliğinin artması, işlevine ulaşması için gerekli olduğu ortaya çıkmıştır.

Örgütsel bağl1lık ile örgütsel vatandaşlık davranışı incelendiğinde aralarında pozitif yönde anlamlı bir ilişkinin olduğu ortaya çıkmıştır. Bu bağlamda okullarda öğretmenlerin örgütsel vatandaşlığ geliştirildiğinde bağlılığın kendiliğinden sağlandığı, okulun bir vatandaşı olamayan öğretmenlerin ise okula bağlılıklarının azaldığı söylenebilir. Buradan hareketle vicdan, erdem, nezâket, sportmenlik ve gönüllülük esasına dayalı bir okul sisteminin kurulması hem örgütsel 
vatandaşlık davranışını arttıracak hem de örgütsel bağlılığı arttıracaktır. Araştırmamızın sonuçları Aslan'ın (2008) ulaştığı sonuçlar ile paralellik göstermektedir.

Örgütsel sinizm ile örgütsel vatandaşlık davranışı arasındaki ilişki incelendiğinde negatif yönde bir ilişkinin olduğu ortaya çıkmıştır. Buradan hareketle örgütsel vatandaşlık davranışının artması örgütsel sinizm azalttı̆̆1, örgütsel sinizmin azalması ise örgütsel vatandaşlık davranışını arttırdığı söylenebilir. Bu durum da örgütsel sinizmin y1kıcı, okulu amaçlarından uzaklaştırıcı etkisinden korunmak, amacını gerçekleştiren okullar yaratabilmek için vatandaşlık davranışları geliştirilmeli sinizm davranışları ötelenerek söndürülmelidir. Araştırmamızın sonuçları İçerli ve Yıldırım (2012), Yetim ve Ceylan (2011) tarafından yapılan araştırma sonuçları ile benzerlik göstermektedir.

Örgütsel bağlılı̆̆ın alt boyutlarından duygusal bağlılık ile devam bağlılığı ve örgütsel vatandaşlık davranışı arasında pozitif yönde düşük düzeyde bir ilişki, duygusal bağlılık ile normatif bağlılık arasında pozitif yönde orta düzeyde, duygusal bağlılık ile örgütsel sinizm arasında negatif yönde düşük düzeyde bir ilişki bulunmuştur. Bu bulgu Yıldız (2013) tarafından yapılan araştırma sonuçları ile benzerlik göstermektedir. Buradan hareketle öğretmenlerin duygusal bağlılığının artması, devam bağlılığı, normatif bağlılık ve örgütsel vatandaşlık davranışını arttırmaktadır. Kendi istekleri ile okulda kalan, saygı, sevgi, ortamının bulunduğu, misyonun ve vizyonun paylaşıldığı okullarda duygusal bağl1lık artacağ buna bağlı olarak da normatif ve devam bağlılığ 1 ile 
örgütsel vatandaşlık davranışı artmakta, okulu olumsuz etkileyen sinizm davranışı azalmakta olduğu söylenebilir.

Örgütsel bağlılığın alt boyutlarından devam bağlılığ ile normatif bağl1lık arasında pozitif yönde orta düzeyde bir ilişki, devam bağlılığı ile örgütsel sinizm ve örgütsel vatandaşlık davranışı arasında pozitif yönde düşük bir düzeyde ilişki bulunmuştur. Bu bulgu Yıldız (2013) tarafından yapılan araştırma sonuçları ile benzerlik göstermektedir. Buradan hareketle devam bağlılı̆̆ının artması öğretmenlerin normatif bağlılıkları, örgütsel sinizmleri ve örgütsel vatandaşlık davranışlarının artmasını sağlamakta olduğu söylenebilir. Okula devam etme sonucunda maddî bir gelir elde edileceğinden dolayı okula bağlılığın artması, ahlâkî bir görevin yapılacağına olan inancı arttırmakta, örgütsel sinizmin artmasını, vatandaşlığın artmasını sağlamaktadır. Buradan hareketle manevî bir bağlılık olmadığından, maddiyatın artması, devam bağlılığını; buna paralel olarak da sinizm ve örgütsel vatandaşlığın artacağı söylenebilir.

Örgütsel bağlılığın alt boyutlarından normatif bağlılık ile örgütsel sinizm arasında negatif yönde düşük, normatif bağlılık ile örgütsel vatandaşlık davranışı arasında pozitif yönde düşük bir ilişki ortaya çıkmıştır. Buradan hareketle normatif bağlılıktaki artış örgütsel sinizmi azaltmakta, örgütsel vatandaşlık davranışını ise arttırmaktadır. Bu bağlamda öğretmenlerin ahlâkî bir görev duygusu ile okulda çalışmasının sinizmin etkilerini azaltarak öğretmenin okulun vatandaşı olmasını sağladığı, okulun performansını ve amacına ulaşmasını kolaylaş- 
tırdığı söylenebilir. Bu sonuçlar doğrultusunda araştıramcılar, öğretmen ve yöneticiler için önerilerimiz şunlardır:

- Yöneticiler okulun amacını gerçekleştirmek için, örgütsel bağlılığ1 ve örgütsel vatandaşlığı geliştirecek aktiviteler yapmalıdirlar.

- Örgütsel sinizmi destekleyen çalışmalar okul ortamından uzaklaştırılmalı, görmezden gelinerek sönmesi sağlanmalıdır,

- Okul örgütlerinde çalışan öğretmenlerin okula bağlılığını arttırmak için görev duygusu geliştirilmeli, kendi istekleri ile okulda kalmaları sağlanmalıdır.

\section{Kaynakça}

Abraham, R. (2000). Organizational cynicism: Bases and consequences. Generic, Social, and General Psychology Monographs, 126(3), 269-292.

Akyol P., Atan T. ve Gökmen B. (2013). Beden eğitimi ve sınıf öğretmenlerinin örgütsel bağlılık düzeylerinin incelenmesi. Spor ve Performans Araştırmaları Dergisi, 1, 38-45.

Allen, N. J. ve Meyer, J. P. (1990). The measurement and antecedents of affective, continuance, and normative commitment to the organization. Journal of Occupational Psychology, 63(1), 1-18.

Arslan, E. T. (2012). Süleyman Demirel Üniversitesi İktisadi ve İdari Bilimler Fakültesi akademik personelinin genel ve örgütsel sinizm düzeyi. Doğuş Üniversitesi Dergisi, 13(1), 12-27.

Aslan, Ş. (2008). Örgütsel vatandaşlık davranışı ile örgütsel bağlılık ve mesleğe bağl1lık arasındaki ilişkilerin incelenmesi. Yönetim ve Ekonomi Dergisi, 15(2), 163-178.

Baş, G. ve Şentürk, C. (2011). İlköğretim okulu öğretmenlerinin ör- 
gütsel adalet, örgütsel vatandaşlık ve örgütsel güven algıları. Kuram ve Uygulamada Ĕ̈itim Yönetimi, 17(1), 29-62.

Blau, G. J. ve Boal, K. B. (1987). Conceptualizing how job involvement and organizational commitment affect turnover and absenteeism. The Academy of Management Review, 12(2), 288-300.

Boylu, Y., Pelit, E. ve Güçer, E. (2007). Akademisyenlerin örgütsel bağl1lık düzeyleri üzerine bir araştırma. Finans Politik \& Ekonomik Yorumlar, 5(11), 55-74.

Brown, B. B. (2003). Employees' organizational commitment and their perception of supervisors' relations-oriented and task-oriented leadership behaviors. Yayımlanmamış doktora tezi, Falls Church, Virginia.

Buluç, B. (2008). Ortaöğretim okullarında örgütsel sağlık ile örgütsel vatandaşlık davranışları arasındaki ilişki. Türk Ĕgitim Bilimleri Dergisi, 6(4), 571-602.

Buluç, B. (2009). Sınıf öğretmenlerinin algılarına göre okul müdürlerinin liderlik stilleri ile örgütsel bağlılık arasındaki ilişki. Kuram ve Uygulamada Eğitim Yönetimi, 15(57), 5-34.

Büyüköztürk, Ş., Kılıç-Çakmak, E., Akgün, Ö. E., Karadeniz, Ş. ve Demirel, F. (2010). Bilimsel araştırma yöntemleri. PegemA: Ankara.

Çetin, M. Ö. (2004). Örgüt kültürü ve örgütsel bă̆lllık. Ankara: Nobel.

Dean, J. W., Brandes, P. ve Dharwadkar, R. (1998). Organizational cynicism. The Academy of Management Review, 23(2), 341-352.

DiPaola, M. F., Tarter, C. J. ve Hoy, W. K. (2005). Measuring organizational citizenship in schools: The OCB scale. W. K. Hoy ve C. Miskel, (Eds.), Educational leadership and reform içinde (319-342). Greenwich, CN: Information Age Publications.

Doğan-Kılıç, E. (2013). İlköğretim okullarında sinizm: Şanlıurfa örneği. Uluslararası Kültür Araştırmaları Dergisi, 2(2), 58-70. 
Erdem, M. (2010). Öğretmen algılarına göre liselerde iş yaşamı kalitesi ve örgütsel bağl1lıkla ilişkisi. Kuram ve Uygulamada Eğitim Yönetimi, 16(4), 511-536.

Güzeller, C. O. ve Kalağan, G. (2008). Örgütsel sinizm ölçeğinin Türkçe'ye uyarlanması ve çeşitli değişkenler açısından eğitim örgütlerinde incelenmesi. 16. Yönetim ve Organizasyon Kongresi Kongre Kitabı içinde (87-94). İstanbul Kültür Üniversitesi.

Helvacı, M. A. ve Çetin, A. (2012). İlköğretim okullarında görev yapan öğretmenlerin örgütsel sinizm düzeylerinin belirlenmesi (Uşak ili örneği). Turkish Studies, 7(3), 1475-1497.

İçerli, L. ve Yıldırım, M. H. (2012). Örgütsel sinizm ve örgütsel vatandaşlık davranışı arasındaki ilişki: Sağlık sektöründe bir araştırma. Organizasyon ve Yönetim Bilimleri Dergisi, 4(1), 167-176.

James, M. S. L. (2005). Antecedents and consequences of cynicism in organizations: An examination of the potential positive and negative effects on school systems. Doktora tezi, ProOuest Dissertations and Theses veri tabanından elde edilmiştir.

Kalağan, G. (2009). Araştırma görevlilerinin örgütsel destek algıları ile örgütsel sinizm tutumları arasındaki ilişki. Yayımlanmamış Yüksek Lisans Tezi, Akdeniz Üniversitesi Sosyal Bilimler Enstitüsü.

Kalağan, G. ve Güzeller, C. O. (2010). Öğretmenlerin örgütsel sinizm düzeylerinin incelenmesi. Pamukkale Üniversitesi Eğitim Fakültesi Dergisi, 27, 83-97.

Korkmaz, M. (2011). İlköğretim okullarında örgütsel iklim ve örgütsel sağlığının örgütsel bağlılık üzerindeki etkisi. Kuram ve Uygulamada Eğitim Yönetimi, 17(1), 117-139.

Koşar, D. ve Yalçınkaya, M. (2013). Öğretmenlerin örgütsel vatandaşlık davranışlarının yordayıcıları olarak örgüt kültürü ve örgütsel güven. Kuram ve Uygulamada Ĕ̈itim Yönetimi, 19(4), 603-627. 
Kurşunoğlu, A., Bakay, E. ve Tanrı̈ğen, A. (2010). İlköğretim okulu öğretmenlerinin örgütsel bağl1lık düzeyleri. Pamukkale Üniversitesi Ĕ̈itim Fakültesi Dergisi, 28(2), 101-115.

Meyer, J. P. ve Allen, N. J. (1984). Testing the "side-bet theory" of organizational commitment: Some methodological considerations, Journal of Applied Psychology, 69, 372-378.

Meyer, J. P. ve Allen, N. J. (1991). A three-component conceptualization of organizational commitment. Human Resource Management Review, 1, 61-89.

Morrow, P. C. (1983). Concept redundancy in organizational research: The case of work commitment. Academy of Management Review, $8(3), 486-500$.

Obeng, K. ve Ugboro, I. (2003). Organizational commitment among public transit employees: an assessment study. Journal of the Transportation Research Forum, 57(2), 83-98.

Oğuz, E. (2011). Öğretmenlerin örgütsel vatandaşlık davranışları ile yöneticilerin liderlik stilleri arasındaki ilişki. Kuram ve Uygulamada Ĕgitim Yönetimi, 17(3), 377-403.

Organ, D. W. (1988). Organizational citizenship behavior: The good soldier syndrome. Lexington, MA: Lexington Books.

Özdevecioğlu, M. (2003). Algılanan örgütsel destek ile örgütsel bağl1lık arasındaki ilişkilerin belirlenmesine yönelik bir araştırma. Dokuz Eylül Üniversitesi I. I. B. F. Dergisi, 18(2), 113-130.

Özgan, H., Külekçi E. ve Özkan M. (2011). Öğretim elemanlarının örgütsel bağlılık düzeyleri arasındaki ilişkinin incelenmesi. International Online Journal of Educational Sciences, 4(1), 196-205.

Özler, D. E., Atalay, C. G. ve Şahin, M. D. (2010). Örgütlerde sinizm güvensizlikle mi bulaşır? Organizasyon ve Yönetim Bilimleri Dergisi, 2(2), 47-55. 
Polat, S. ve Celep, C. (2008). Ortaöğretim öğretmenlerinin örgütsel adalet, örgütsel güven, örgütsel vatandaşlık davranışlarına ilişkin alg1ları. Kuram ve Uygulamada Ĕ̈itim Yönetimi, 54(2), 307-331.

Schappe, S. P. (1998). The influence of job satisfaction, organisational commitment, and fairness perceptions on organizational citizenship behavior. The Journal of Psychology, 132(3), 277-290.

Sezgin, F. (2005). Örgütsel vatandaşlık davranışları: Kavramsal bir çözümleme ve okul açısından bazı çıkarımlar. Gazi Eğitim Fakültesi Dergisi, 25(1), 317-339.

Sezgin, F. (2010). Öğretmenlerin örgütsel bağl1lı̆gının bir yordayıcısı olarak okul kültürü. Eğitim ve Bilim, 35(156), 142-159.

Stanley, D. J. (1998). Employee cynicism about organizational change: Development and validation of a measure. Yayımlanmamış yüksek lisans tezi, The University of Western Ontorio. ProOuest Dissertations and very tabanından edinilmiştir.

Taşdan, M. ve Yılmaz, K. (2008). Organizational citizenship and organizational justice scales' adaptation to Turkish. TED Eğitim ve Bilim Dergisi, 33(150), 87-96.

Tsui, K. T. ve Cheng, Y. C. (1999). School organizational health and teacher commitment: A contingency study with multi-level analysis. Educational Research and Evaluation, 5(3), 249-268.

Uygur, M. ve Yıldırım, A. (2011). İlköğretim okulu yöneticilerinin kültürel liderlik rolleri ile öğretmenlerin örgütsel bağl1lı̆ğ arasındaki ilişki. Gazi Üniversitesi Endüstriyel Sanatlar Eğitim Fakültesi Dergisi, 27, 72-81.

Yetim, S. A. ve Ceylan, Ö. Ö. (2011). Örgütsel sinizm ve örgütsel vatandaşlık davranışları arasındaki ilişkiyi belirlemeye ilişkin bir araştırma. E-Journal of New World Sciences Academy, 6(1), 682-695.

Yıldız, K. (2013). Örgütsel bağl11ık ile örgütsel sinizm ve örgütsel 
muhalefet arasındaki ilişki. Turkish Studies, 8(6), 853-879.

Yörük, S. ve Sağban, Ş. (2012). Okul müdürlerinin kültürel liderlik rollerinin öğretmenlerin örgütsel bağl1lık düzeyine etkisi. Turkish Studies, 7(3), 2795-2813. 